14.7-27.3\% of pts had initial PROMIS T-scores within 0.5SD of normal. There was a significant $(p<0.0001)$ relationship between $\mathrm{PI}$ and $\mathrm{F} T$ scores and the respective 4 questions on the P29v2.

Conclusion: Avoiding floor effects in pts who initiated TNFi therapy with near-normal PROMIS scores, PROMIS instruments demonstrated a robust T-score change in response to initiation of TNFi therapy.

Disclosure of Interests: Clifton Bingham Grant/research support from: BMS, Consultant for: AbbVie, BMS, Eli Lilly, Genentech/Roche, Janssen, Pfizer, Sanofi/Regeneron, Sergio Schwartzman Shareholder of: Amgen, Boston Scientific, Gilead, Medtronic, and Pfizer, Consultant for: AbbVie, Crescendo, Dermtech, Janssen, Gilead, Lilly, Myriad, Novartis, Regeneron, Samsung, Sanofi, and Union Chimique Belge, Speakers bureau: Abbott/ AbbVie, Genentech, Janssen, Lilly, Novartis, Pfizer, Regeneron, Sanofi, and Union Chimique Belge, Shelly Kafka Shareholder of: J\&J, Employee of: J\&J, Dennis Parenti Employee of: Janssen Research \& Development, LLC, Shawn Black Employee of: Janssen Research \& Development, LLC, Stephen Xu Employee of: Employee of Janssen Research \& Development, LLC, Wayne Langholff Employee of: Janssen Research \& Development, LLC, Jeffrey Curtis: None declared

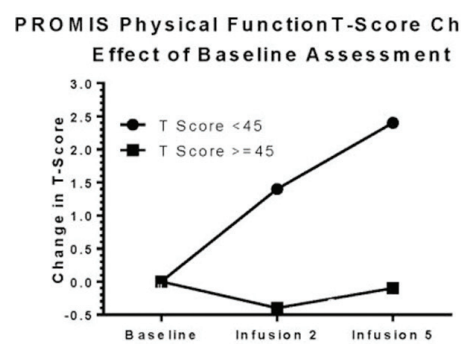

PROMIS Pain Interference SF6b T-Score Change:

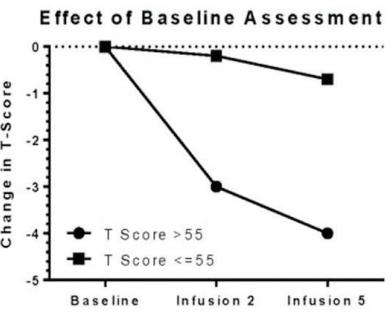

PROMIS Fatigue SF 7a T-Score Change: Effect of Baseline Assessment

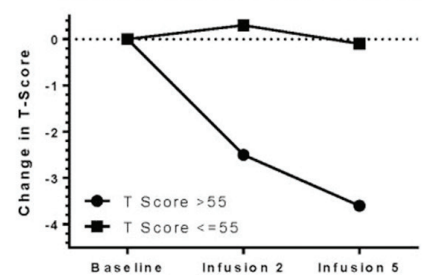

Figure 1

DOI: 10.1136/annrheumdis-2019-eular.572

\section{AB0385 INTEGRATED SAFETY ANALYSIS ACROSS PHASE 3 CLINICAL STUDIES INCLUDING THE CONTROLLED AND UNCONTROLLED PERIODS FOR INTRAVENOUS GOLIMUMAB IN RHEUMATOID ARTHRITIS, PSORIATIC ARTHRITIS, AND ANKYLOSING SPONDYLITIS}

Atul Deodhar ${ }^{1}$, M Elaine Husni ${ }^{2}$, Sergio Schwartzman ${ }^{3}$, Shelly Kafka ${ }^{4}$, Soumya D. Chakravarty ${ }^{4,5}$, Elizabeth C. Hsia ${ }^{6,7}$, Diane D. Harrison ${ }^{6}$, Jocelyn H. Leu ${ }^{6}$, Yiying Zhou ${ }^{6}$, Kim Hung Lo ${ }^{6}$, Arthur Kavanaugh ${ }^{8} .{ }^{1}$ Oregon Health and Science Univ., Portland, United States of America; ${ }^{2}$ Cleveland Clinic, Cleveland, United States of America; ${ }^{3}$ Weill Cornell Medical College, New York, United States of America; ${ }^{4}$ Janssen Pharmaceuticals, Horsham, United States of America; ${ }^{5}$ Drexel Univ College of Med, Phila, United States of America; ${ }^{6}$ Janssen Research and Development, LLC, Spring House, United States of America; ${ }^{7}$ Univ of Penn Medical Center, Phila, United States of America; ${ }^{8}$ Univ. of California San Diego, San Diego, United States of America

Background: The GO-FURTHER, GO-VIBRANT, and GO-ALIVE randomized controlled trials evaluated the efficacy and safety of intravenous
(IV) golimumab (GLM) in patients (pts) with active rheumatoid arthritis (RA), psoriatic arthritis (PsA), and ankylosing spondylitis (AS), respectively.

Objectives: This integrated analysis assessed safety events across indications in pts who received IV GLM.

Methods: Integrated safety data from 3 Phase 3, double-blind, placebo (PBO)-controlled trials were analyzed up to week (WK) 112 in RA pts and up to WK 60 in PsA and AS pts. Pts received either IV PBO or IV GLM (2 mg/kg) at $0,4,12$, and 20 WKS. PBO pts crossed over to IV GLM at WK 24, except RA pts randomized to PBO who met early escape criteria crossed over at WK 16 and AS pts randomized to PBO who crossed over at WK 16. Cumulative adverse events (AEs) were reported by indication and pooled by treatment. Anti-drug antibodies (ADAs) were evaluated.

Table 1

\begin{tabular}{|c|c|c|c|c|}
\hline Variables & $\begin{array}{c}\mathrm{RA}^{2} \\
\text { IV GLM }\end{array}$ & $\begin{array}{l}\text { PsA } \\
\text { IV GLM }\end{array}$ & $\begin{array}{c}\text { AS }^{b} \\
\text { IV GLM }\end{array}$ & $\begin{array}{c}\text { All } \\
\text { IV GLM }\end{array}$ \\
\hline Treated patients, $n$ & 584 & 460 & 204 & 1248 \\
\hline Average duration of follow up, wks & 95.9 & 47.2 & 51.8 & 70.7 \\
\hline $\begin{array}{l}\text { Patients who discontinued due to } \\
\text { an } \mathrm{AE}\end{array}$ & $41(7.0)$ & $17(3.7)$ & $4(2.0)$ & $62(5.0)$ \\
\hline Patients with $\geq 1 \mathrm{AE}$ & $462(79.1)$ & $234(50.9)$ & $113(55.4)$ & $809(64.8)$ \\
\hline Patients with $\geq 1 \mathrm{SAE}$ & $106(18.2)$ & $24(5.2)$ & $7(3.4)$ & $137(11.0)$ \\
\hline Patients with $\geq 1$ infection & $287(49.1)$ & $105(22.8)$ & $67(32.8)$ & $459(36.8)$ \\
\hline Patients with $\geq 1$ serious infection & $36(6.2)$ & $10(2.2)$ & $3(1.5)$ & $49(3.9)$ \\
\hline Patients with $\geq 1$ infusion reaction & $27(4.6)$ & $4(0.9)$ & $3(1.5)$ & $34(2.7)$ \\
\hline ADA-positive patientsc, $\%$ & 23.4 & 22.0 & 20.2 & 22.3 \\
\hline \multicolumn{5}{|c|}{$\begin{array}{l}\text { Patients } n \text { (\%) reporting safety events during the placebo-controlled and uncontrolled study periods are } \\
\text { reported, unless otherwise specified. } \\
\text { aBased on safety events that occurred up to week } 112 ; \text {; }{ }^{B} \text { Based on safety events that occurred up to week } 60 \\
\text { "Assessed using a drug-tolerant enzyme immunoassay based on IV GLM patients with appropriate samples } \\
\text { through week } 52 \text { (RA, n=552; PsA, n=450; AS, n=203; and All, n=1205) } \\
\text { ADA, anti-drug antibody; AE, adverse event; AS, ankylosing spondylitis; IV GLM, intravenous golimumab; PSA, } \\
\text { psoriatic arthritis; RA, rheumatoid arthritis; SAE, serious adverse event }\end{array}$} \\
\hline
\end{tabular}

Table 2

\begin{tabular}{|c|c|c|c|c|c|c|c|c|}
\hline \multirow{2}{*}{ Variables } & \multicolumn{2}{|c|}{$\mathrm{RA}^{2}$} & \multicolumn{2}{|c|}{ PsA } & \multicolumn{2}{|c|}{$A S^{b}$} & \multicolumn{2}{|c|}{ All } \\
\hline & IV GLM & Placeb & IV GLM & Placebo & IV GLM & Placebo & IV GLM & Placebo \\
\hline Treated patients, $\mathrm{n}$ & 584 & 197 & 460 & 239 & 204 & 103 & 1248 & 539 \\
\hline $\begin{array}{l}\text { Average duration of follow } \\
\text { up, wks }\end{array}$ & 95.9 & 21.0 & 47.2 & 23.2 & 51.8 & 16.1 & 70.7 & 21.0 \\
\hline Opportunistic infections & 0.4 & 0 & 0 & 0 & 0 & 0 & 0.2 & 0 \\
\hline (95\% confidence interval) & $(0.1,1.0)$ & $(0,3.8)$ & $(0,0.7)$ & $(0,2.8)$ & $(0,1.5)$ & $(0,9.4)$ & $(0.1,0.6)$ & $(0,1.4)$ \\
\hline All malignancies & 0.5 & 0 & 0.5 & 1.9 & 0 & 0 & 0.4 & \\
\hline ( $95 \%$ confidence interval) & $(0.2,1.1)$ & $(0,3.8)$ & $(0.1,1.7)$ & $(0.2,6.8)$ & $(0,1.5)$ & $(0,9.4)$ & $(0.2,0.9)$ & $(0.1,3.3)$ \\
\hline Active TB & & & & & 0.5 & & 0.3 & \\
\hline ( $95 \%$ confidence interval) & $(0,0.7)$ & $(0,3.8)$ & $(0.1,1.7)$ & $(0,2.8)$ & $(0,2.7)$ & $(0,9.4)$ & $(0.1,0.7)$ & $(0,1.4)$ \\
\hline Death & 0.5 & 1.3 & 0.2 & & & 0 & & 1.4 \\
\hline (95\% confidence interval) & $(0.2,1.1)$ & & $(0,1.3)$ & $(0.2,6.8)$ & $(0,1.5)$ & $(0,9.4)$ & $(0.1,0.8)$ & $(0.3,4.0)$ \\
\hline \multicolumn{9}{|c|}{$\begin{array}{l}\text { Incidence per } 100 \text { patient-years are reported, unless otherwise specified. } \\
\text { "Based on safety events that occurred up to week } 112 \\
\text { bBased on safety events that occurred up to week } 60\end{array}$} \\
\hline $\begin{array}{l}\text { AS, ankylosing spondylitis; IV } \\
\text { tuberculosis }\end{array}$ & & & & & & & & \\
\hline
\end{tabular}

Results: Overall, 1248 pts were treated with IV GLM across indications. A numerically greater proportion (\%) of IV GLM pts with RA reported safety events than pts with PsA or AS (Table 1): SAEs (18.2 vs 5.2 vs 3.4 ), infections (49.1 vs 22.8 vs 32.8 ), serious infections (6.2 vs 2.2 vs 1.5 ), and infusion reactions (4.6 vs 0.9 vs 1.5). Incidence (per 100 ptyears) of opportunistic infections, malignancy, active tuberculosis, and death with IV GLM was low ( $\leq 0.5$ ) across indications (Table 2). Infections were the most commonly reported type of SAE among pooled IV GLM pts; the most frequent was pneumonia (10 [0.8\%]). Incidence (per 100 pt-years) of serious infections was similar among IV GLM pts with and without corticosteroid use (3.35 vs 3.37, respectively). Overall, 1 IV GLM pt (PsA) experienced a demyelination event. A numerically greater proportion of IV GLM pts discontinued due to an AE than PBO pts $(5.0 \%$ vs $0.9 \%$, respectively). In IV GLM pts with baseline alanine aminotransferase $(\mathrm{ALT}) \leq$ upper limit of normal (ULN), $1.2 \%$ had post-baseline ALT elevations $>5 \mathrm{X}$ ULN. The proportion of IV GLM and PBO pts with post-baseline ALT elevations $\geq 5 \mathrm{X}$ ULN was $2.1 \%$ vs $0 \%$ with methotrexate and $0.7 \%$ vs $1.4 \%$ without methotrexate use at baseline, respectively. Using a drug-tolerant enzyme immunoassay, the incidence of ADAs was $22 \%$ through WK 52 across indications, which primarily consisted of low titer ADAs.

Conclusion: IV GLM demonstrated a consistent safety profile across indications in the PBO-controlled (up to WK 24) and uncontrolled study periods. Similar to WK 24 (1), more safety events occurred in RA pts, who represented the largest study population with older pts, longer disease duration, and more concomitant medication use. 


\section{REFERENCES}

[1] Husni ME, et al. Presented at EULAR 2018, Amsterdam, the Netherlands.

Disclosure of Interests: Atul Deodhar Grant/research support from: AbbVie, Amgen, Eli Lilly, GSK, Janssen, Novartis, Pfizer, and UCB, Consultant for: AbbVie, Amgen, BMS, Eli Lilly, Janssen, Novartis, Pfizer, and UCB, M Elaine Husni Grant/research support from: Janssen, Sergio Schwartzman Shareholder of: Amgen, Boston Scientific, Gilead, Medtronic, and Pfizer, Consultant for: AbbVie, Crescendo, Dermtech, Janssen, Gilead, Lilly, Myriad, Novartis, Regeneron, Samsung, Sanofi, and Union Chimique Belge, Speakers bureau: Abbott/AbbVie, Genentech, Janssen, Lilly, Novartis, Pfizer, Regeneron, Sanofi, and Union Chimique Belge, Shelly Kafka Shareholder of: J\&J, Employee of: J\&J, Soumya D Chakravarty Shareholder of: Johnson \& Johnson, Employee of: Johnson \& Johnson, Elizabeth C Hsia Employee of: Employee of Janssen Research \& Development, LLC, Diane D Harrison Employee of: Janssen Research \& Development, LLC, Jocelyn H Leu Employee of: Janssen Research \& Development, LLC, Yiying Zhou Employee of: Janssen Research \& Development, LLC, Kim Hung Lo Employee of: Janssen Research \& Development, LLC, Arthur Kavanaugh Grant/research support from: UCB Pharma DOI: 10.1136/annrheumdis-2019-eular.179

\section{AB0386 RESPONSE TO BIOLOGIC THERAPY IS INFLUENCED BY THE BODY MASS INDEX IN PATIENTS WITH RHEUMATOID ARTHRITIS}

Hitoshi Kodera ${ }^{1}$, Yoshiko Sato ${ }^{2}$, Yoshifuji Matsumoto ${ }^{1} .{ }^{1}$ Kuwana city medical center, Kuwana, Japan, ${ }^{2}$ Yokkaichi Hazu medical center, Yokkaichi, Japan

Background: Biologic therapies have been bringing huge advantage in the treatment of rheumatoid arthritis, but response to the therapy is heterogeneous. The influence of the body mass index to the treatment is still controversial.

Objectives: To identify the factors influencing in the response to biologic therapy (bio naïve).

Methods: The analysis of the patients with rheumatoid arthritis who were initiated biologics therapy (bio naïve) between January 2011 to December 2016 in the rheumatology department of a hospital in Japan, was conducted. The effects were evaluated by EULAR response criteria after 6 months of biologic therapy, and factors influencing the response were analyzed in terms of the baseline characteristics (sex, age, disease duration, body mass index, tender joint count, swollen joint count, Patient's visual analog scale, Doctor's visual analog scale, erythrocyte sedimentation rate, C-reactive protein, Disease Activity Score in 28 joints, Modified Health Assessment Questionnaire, Methotrexate use, Prednisolone use).

Table 1.

Table 1. Difference of the baseline characteristics of RA patients between "Good or Moderate response" and "No response" of EULAR response criteria after 6 months of biologic therapy.

\begin{tabular}{|c|c|c|c|}
\hline & \\
\hline & $\begin{array}{l}\text { Good or Moderate response } \\
(\mathrm{n}=82)\end{array}$ & $\begin{array}{c}\text { No response } \\
(\mathrm{n}=63)\end{array}$ & $\mathrm{p}$-value \\
\hline Female sex, no. $(\%)$ & $69(84.1 \%)$ & $53(84.1 \%)$ & 0.9975 \\
\hline Age, years & $55.4 \pm 15.6$ & $59.2 \pm 12.9$ & 0.1115 \\
\hline Disease duration, years & $6.6 \pm 3.6$ & $7.8 \pm 3.9$ & 0.0477 \\
\hline $\mathrm{BMI}, \mathrm{kg} / \mathrm{m}^{2}$ & $22.0 \pm 3.4$ & $24.4 \pm 5.2$ & 0.0008 \\
\hline$\geq 25$, no. $(\%)$ & $12(14.6 \%)$ & $22(35 \%)$ & 0.0043 \\
\hline TJC & $5.6 \pm 6.1$ & $4.0 \pm 5.4$ & 0.0972 \\
\hline SJC & $3.4 \pm 4.8$ & $1.5 \pm 2.4$ & 0.0018 \\
\hline Patient's VAS (range 0-100) & $46.6 \pm 24.6$ & $34.4 \pm 27.4$ & 0.0052 \\
\hline Doctor's VAS (range 0-100) & $44.6 \pm 25.8$ & $34.3 \pm 28.0$ & 0.0223 \\
\hline ESR mm/hour & $62.8 \pm 34.2$ & $59.0 \pm 31.8$ & 0.5702 \\
\hline $\mathrm{CRP} \mathrm{mg} / \mathrm{dL}$ & $1.7 \pm 2.1$ & $0.9 \pm 1.7$ & 0.0094 \\
\hline DAS28-ESR & $4.9 \pm 1.2$ & $4.2 \pm 1.3$ & 0.0015 \\
\hline DAS28-CRP & $3.9 \pm 1.2$ & $3.1 \pm 1.3$ & $<.0001$ \\
\hline $\mathrm{mHAQ}$ & $0.5 \pm 0.5$ & $0.5 \pm 0.6$ & 0.3829 \\
\hline \multicolumn{4}{|l|}{ Concomitant therapy } \\
\hline MTX, no. (\%) & $62(75.6 \%)$ & $47(74.6 \%)$ & 0.8894 \\
\hline MTX dose, $\mathrm{mg} /$ week & $7.4 \pm 4.6$ & $7.8 \pm 5.0$ & 0.7134 \\
\hline Steroid, no. $(\%)$ & $46(56.1 \%)$ & $48(76.2 \%)$ & 0.0120 \\
\hline Prednisolone dose, mg/day & $1.6 \pm 2.3$ & $3.9 \pm 8.8$ & 0.5156 \\
\hline
\end{tabular}

Table 2.

Table 2. Logistic regression analysis of "Good or Moderate response" of EULAR response criteria Table 2. Logistic regression analysis of "Good or Moderate response" of EULAR response criteria
after 6 months of biologic therapy by baseline body mass index among Tumor Necrosis Factor users, after 6 months of biologic therapy by baseline body
IL-6-receptor inhibitor users and CTLA4-Ig users.

\begin{tabular}{lccc}
\hline Biologics & Odds Ratio & 95\% confidence interval & $\mathrm{p}$-value \\
\hline TNF inhibitor & 0.88 & $0.78-0.99$ & 0.0428 \\
IL-6 receptor inhibitor & 0.75 & $0.61-0.93$ & 0.0093 \\
CTLA4-Ig & 0.95 & $0.79-1.13$ & 0.5757
\end{tabular}

Results: There were differences of baseline characteristics in disease duration and body mass index between the patients who achieved "Good or Moderate response" and "No response" of EULAR response criteria after 6 months of biologic therapy (table 1). The latter was more significant, and the difference was found among biologics (table 2).

Conclusion: Body mass index influence in the response to first biologic therapy in patients with rheumatoid arthritis.

Disclosure of Interests: None declared

DOI: 10.1136/annrheumdis-2019-eular.5170

\section{AB0387 SATISFACTION OF PATIENTS AND PHYSICIANS WITH TREATMENTS FOR RHEUMATOID ARTHRITIS: A NATIONWIDE SURVEY IN CHINA}

Nan Jiang ${ }^{1}$, Pingting Yang ${ }^{2}$, Shengyun $\mathrm{Liu}^{3}$, LI Hongbin ${ }^{4}$, Lijun $\mathrm{Wu}^{5}$, Xiaofei Shi ${ }^{6}$ Yongfei Fang ${ }^{7}$, Yi Zhao ${ }^{8}$, Jian $\mathrm{Xu}^{9}$, Zhenyu Jiang ${ }^{10}$, Zhenbiao $\mathrm{Wu}^{11}$, Xingwang Duan ${ }^{12}$, Qian Wang ${ }^{1}$, Xinping Tian ${ }^{1}$, Mengtao Li ${ }^{1}$, Xiaofeng Zeng ${ }^{1}$. ${ }^{1}$ Department of Rheumatology, Peking Union Medical College Hospital, Beijing, China; ${ }^{2}$ Department of Rheumatology and Immunology, First Affiliated Hospital, China Medical University, Shenyang, China: ${ }^{3}$ Department of Rheumatology, the First Affiliated Hospital of Zhengzhou University, Zhengzhou, China; ${ }^{4}$ Department of Rheumatology, Affiliated Hospital of Inner Mongolia Medical College, Hohhot, China; ${ }^{5}$ Department of Rheumatology and Immunology, People's Hospital of Xinjiang Uygur Autonomous Region, Urumqi, China; ${ }^{6}$ Department of Rheumatology and Immunology, the First Affiliated Hospital, and College of Clinical Medicine of Henan University of Science and Technology, Luoyang, China; ${ }^{7}$ Department of Rheumatology, Southwest Hospital, Third Military Medical University, chongqing, China; ${ }^{8}$ Department of Rheumatology and Immunology, West China Hospital, Sichuan University, Chengdu, China; ${ }^{9}$ Department of Rheumatology and Immunology, First Affiliated Hospital of Kunming Medical University, Kunming, China; ${ }^{10}$ Department of Rheumatology, the First Hospital of Jilin University, Changchun, China; ${ }^{11}$ Department of Clinical Immunology and Rheumatology, Xijing Hospital affiliated to the Fourth Military Medical University, Xi'an, China; ${ }^{12}$ Department of Rheumatology, The Second Affiliated Hospital of Nanchang University, Nanchang, China

Background: Treatment satisfaction is important for adherence to therapy both for patients and physicians. There is no full understanding of the treatment satisfaction for rheumatoid arthritis (RA) in China.

Objectives: The aim is to explore the treatment satisfaction between rheumatologists and RA patients across China and the factors associated with patients' satisfaction.

Table 1.

\begin{tabular}{|c|c|c|c|c|}
\hline Treatment & & Patients & Physicians & $P$ \\
\hline $\begin{array}{ll}\text { All medications for } \\
\text { patients/ csDMARDs for } \\
\text { physicians }\end{array}$ & N & 1237 & 146 & \\
\hline Effectiveness & Median (range) & $83.3(0-100)$ & $66.7(33.3-100)$ & \\
\hline Side effects & Median (range) & $\begin{array}{l}100 \\
100)\end{array}$ & $75(16.7-100)$ & \\
\hline Convenience & Mcdian (rangc) & $\begin{array}{l}81.3 \\
100)\end{array}$ & $68.8(31.3-100)$ & \\
\hline Global satisfaction & Median (range) & $\begin{array}{l}83.3 \\
100)\end{array}$ & $66.7(16.7-100)$ & \\
\hline bDMARDs & $N$ & 335 & 146 & \\
\hline Effectiveness & Median (range) & $83.3(0-100)$ & $75(33.3-100)^{*}$ & 0.302 \\
\hline Side effects & Median (range) & $100(8.3-100)$ & $\begin{array}{l}87.5 \\
100)^{*}\end{array} \quad(16.7-$ & $<0.001$ \\
\hline Convenience & Median (range) & $75(0-100)$ & $68.8(12.5-100)$ & 0.001 \\
\hline Global satisfaction & Median (range) & $75(0-100)$ & $75(16.7-100)^{*}$ & 0.889 \\
\hline
\end{tabular}

